\title{
Sex Determination During Inflorescence Bud Differentiation in Monoecious Pistacia chinensis Bunge
}

\author{
Qian Bai ${ }^{1,2}$, Chenyi Zhu ${ }^{1}$, Xia Lei ${ }^{1}$, Tao Cao ${ }^{1}$, Shuchai Su ${ }^{1,2, * \mathbb{C}}$ and Pingsheng Leng ${ }^{3}$ \\ 1 Ministry of Education Key Laboratory of Silviculture and Conservation, College of Forestry, \\ Beijing Forestry University, 35 East Qinghua Road, 100083 Beijing, China; baiqian@bjfu.edu.cn (Q.B.); \\ ChenyiZhu@pku.edu.cn (C.Z.); alisha18511929701@bjfu.edu.cn (X.L.); 201721180008@mail.bnu.edu.cn (T.C.) \\ 2 National Energy R\&D Center for Non-food Biomass, Beijing Forestry University, 35 East Qinghua Road, \\ 100083 Beijing, China \\ 3 College of Landscape Architecture, Beijing University of Agriculture, 102206 Beijing, China; \\ lengpsh@bua.edu.cn \\ * Correspondence: sushuchai@bjfu.edu.cn; Tel.: +86-135-5283-1600
}

Received: 11 January 2019; Accepted: 25 February 2019; Published: 26 February 2019

\begin{abstract}
Pistacia chinensis Bunge is widely acknowledged to be dioecious, but rare monoecious individuals have been found. However, the origin of monoecism and the sex differentiation of different sex types remain intriguing questions. Here, sex expressions were explored by identification of sex-associated DNA markers, determination of the sex stability after grafting, and histological characterization of inflorescence bud development using anatomical analysis. The results showed that (1) although polymorphisms among individuals existed, the banding patterns of Polymerase Chain Reaction (PCR) products for different sex types on the same monoecious tree were consistent; (2) the sex expressions of grafted trees were not consistent with those of scions, indicating that monoecism probably did not originate from a stable bud mutation; and (3) both males and females underwent a bisexual period, then the stamen primordia in female buds degenerated into the second round tepals, while the pistil primordia in male buds gradually disappeared. During the sex differentiation phase, female buds were spindle-shaped, while the male buds were full teardrop-shaped, and male buds were bigger than female buds. Taken together, no sex-associated DNA marker was found, sex expressions were unstable after grafting, and the alternative sex organs appeared in the early stage of sex differentiation, suggesting that sex determination occurred during floral development instead of the early vegetative period. These results indicated that the sex expressions may be affected by environmental factors, increasing the understanding of sex determination mechanisms in P. chinensis and other species.
\end{abstract}

Keywords: Pistacia chinensis Bunge; monoecious; molecular markers; sex determination; flower development; grafting

\section{Introduction}

Pistacia chinensis Bunge has been recognized as an important biodiesel tree species in China due to the high oil content of its fruit [1]. It is generally perceived as dioecious [2], and its flowers are unisexual and wind-pollinated, as in other Pistacia species [3]. Thus, the non-fruit-bearing (male) trees are indispensable for pollination, which increases the cost, labor, and field space needed for producing fruit. However, several cases of monoecious Pistacia species have been reported [4-11]. Moreover, our previous work has shown that pollen and ovaries from monoecious $P$. chinensis are fertile [12]. Therefore, monoecious genotypes could produce fruit without male trees, which could 
break the dioecious-based restrictions and increase yield. Nevertheless, due to male and female shoots in monoecious $P$. chinensis both showing evidence of alternate bearing [11], the yield is directly affected by sex type and the number and quality of flower buds [13]. However, the determination mechanisms of both monoecious and dioecious Pistacia species remain unclear. Thus, the finding of monoecious Pistacia can provide valuable resources for research on sex determination mechanisms and breeding programs, such as genomic selection [14], which could promote the development and utilization of monoecious genotypes.

At the DNA level, many studies have tried to develop a rapid method to determine sex in the Pistacia genus using random amplified polymorphic DNA, sequence-characterized amplified region (SCAR), and inter-simple sequence repeat markers that may be able to select the best seedlings and configurations of female and male trees [7,15-25]. However, although a large number of primers were screened, only a few could identify sex differences. For example, Hormaza et al. [15] found just one sex-associated marker (OPO08) after screening 1000 primers in Pistacia vera, suggesting that sex-related loci genes are small or few in number [22]. Furthermore, few primers can accurately (100\%) distinguish between sexes. For instance, Kamiab et al. [26] showed that an error rate of 15\% is possible in the sex determination of P. vera using OPO08. Although 17 sex-linked single nucleotide polymorphism markers were found using restriction-site associated DNA sequencing, they were ineffective for sex determination in other Pistacia species $[27,28]$. Therefore, the sex determination mechanism of $P$. chinensis and the origin of monoecism are still unknown.

While determining the sex molecular mechanism is hard to achieve, it is clear that sexual expression in plants is mainly restricted to flower organogenesis or reproductive organ differentiation [29]. Many studies have hypothesized that dioecism evolved from hermaphroditic ancestors $[30,31]$. According to the developmental stage in which differences between the sexes can be detected, dioecious plants are divided into three classes: Type 1, those in which flower buds rarely form the primordia of the opposite sex; Type 2, those in which the development of opposite sex primordia is initiated but then arrests in the early stages; and Type 3, those in which the development of organs of the opposite sex is arrested at much later stages [29,32]. Although Pistacia species are almost exclusively dioecious, rudimentary female organs are present in the mature male flowers of most Pistacia species (Type 3), including P. atlantica, P. lentiscus, P. terebinthus, P. weinmannifolia, P. palaestina, and P. khinjuk [2,33]. Generally, the mature florets of P. vera and P. chinensis are unisexual; however, rare bisexual florets of $P$. chinensis have recently been found [11]. Furthermore, Hormaza and Polito [34] have reported that vestigial organs of the opposite sex have appeared during flower bud development in P. vera (Type 2). All these phenomena suggest that Pistacia species may have originated from hermaphroditic ancestors. In other words, they may have the molecular basis to become hermaphroditic, and genetic mutations, environmental factors, or epigenetic factors could lead to separate sexes or atavism. For P. chinensis, although the differentiation process of dioecious female flower buds and vegetative buds has been uncovered [35,36], and the reproduction structures near anthesis of dioecious plants have been reported [37], the development of male flower buds is not yet clear. Consequently, studying the difference between male and female buds and the origin of monoecious $P$. chinensis will provide more clues on sex differentiation and evolution of Pistacia species.

To sum up, many issues involving sex determination at both the molecular and morphological (ontogenetic progression) levels still remain. For example, if the sex-linked marker of dioecious $P$. chinensis were found, could monoecism be identified as male, female, or a third sex type? Do different parts that express different sexes on the same monoecious trees show different amplification patterns? Did monoecism originate through a stable genetic mutation or through environmental effects? When do sex differences appear and how are the different sex types determined? To answer these questions, Polymerase Chain Reaction (PCR)-based molecular markers, which have been effective for sex identification in Pistacia species, were used to analyze female, male, and different sex types on monoecious $P$. chinensis. Additionally, to determine whether the monoecism originated from bud mutations (resulting from local genetic alteration and producing a permanent modification), sex 
stability was observed by grafting the shoots that expressed different sex types on monoecious plants. Moreover, the sexual development of male and female flower buds on monoecious $P$. chinensis was observed to provide new information regarding sex expression in monoecious $P$. chinensis.

\section{Materials and Methods}

\subsection{Sex Identification Using PCR-Based Molecular Markers}

\subsubsection{Plant Materials and Genomic DNA Isolation}

Monoecious individuals were found in Tang County, Hebei Province, China $\left(114^{\circ} 27^{\prime}-115^{\circ} 03^{\prime} \mathrm{E}\right.$, $\left.38^{\circ} 37^{\prime}-39^{\circ} 09^{\prime} \mathrm{N}\right)$. All of the $P$. chinensis were discretely distributed within a natural population. Before being sampled, the shoots of different sexes (bearing female, male, and bisexual flowers) on monoecious trees were painted with different colors during the blooming period in April 2015. When the new shoots and leaves spread out during the initial differentiation phase in early May, fresh leaves were collected from 15 individuals, these being five female, five male, and five monoecious P. chinensis. Among them, the different sex types of monoecious trees were sampled separately based on their inflorescences' sex types according to the painted markers. The samples were immediately frozen in liquid nitrogen and stored at $-80^{\circ} \mathrm{C}$ until use. Genomic DNA extractions were performed with a Plant Genomic DNA kit (Tiangen Biotech Co., Beijing, China). Female-pooled and male-pooled DNA samples were prepared by mixing the DNA of five male and five female individuals, respectively, while the monoecious samples were individually (without being pooled) prepared for PCR amplification.

\subsubsection{PCR and SCAR-PCR Amplification}

Eighteen random amplified polymorphic DNA primers, an inter-simple sequence repeat primer pair, and five pairs of SCAR primers (Table 1), which had been screened for sex identification in the Pistacia genus, were used. PCR amplification was performed on a Thermal Cycler S1000 (Bio-Rad Laboratories, Hercules, CA, USA), and PCR cycles were determined according to the references listed in Table 1. Amplified products were separated by electrophoresis in 1-1.2\% agarose gels and then observed under UV light using Gel Logic 212 Imaging Systems (Eastman Kodak Company, Rochester, NY, USA) after ethidium bromide staining.

Table 1. Sequences tested for use in sex determination in Pistacia chinensis.

\begin{tabular}{|c|c|c|c|c|}
\hline & Primer & Sequence & Species & References \\
\hline 1 & OPO-08 & CCTCCAGTGT & P. vera & $\begin{array}{l}\text { Hormaza et al., 1994; } \\
\text { Tan et al., 2003; } \\
\text { Yakubov et al., 2005 }\end{array}$ \\
\hline 2 & BC1200 & GCCTGATTGC & P. vera & $\begin{array}{c}\text { Davarynejad et al., 2012; } \\
\text { Esfandiyari et al., } 2010\end{array}$ \\
\hline 3 & OPP-03 & CTGATACGCC & & Andinova et al., 2006 \\
\hline 6 & OPA-12 & TCGGCGATAG & & Andinova et al., 2006 \\
\hline 7 & OPAD-16 & AACGGGCGTC & & Andinova et al., 2006 \\
\hline 8 & OPK-09 & CCCTACCGAC & P. terebinthus & $\begin{array}{l}\text { Avanzato et al., 2004; } \\
\text { Avanzato and Quarta } \\
2004\end{array}$ \\
\hline 13 & S267 & CTGGACGTCA & P. chinensis & Cheng 2011 \\
\hline 14 & S1420 & AAGGCTCACC & P. chinensis & Cheng 2011 \\
\hline 15 & S1421 & AGCAGCGCAC & P. chinensis & Cheng 2011 \\
\hline 16 & S1426 & GTGGAGTCAG & P. chinensis & Cheng 2011 \\
\hline 17 & S1 & GTTTCGCTCC & P. chinensis & Sun et al., 2014 \\
\hline 18 & S281 & GTGGCATCTC & P. chinensis & Sun et al., 2014 \\
\hline
\end{tabular}


Table 1. Cont.

\begin{tabular}{|c|c|c|c|c|}
\hline & Primer & Sequence & Species & References \\
\hline $19-1$ & S-a & ACACACACACACACACCG & P. vera & \multirow{2}{*}{ Ehsanpour et al., 2009} \\
\hline $19-2$ & S-b & ACACACACACACACACTA & P. vera & \\
\hline $20-2$ & S1421-11CR & CTTCTCGGACTAGCACGGCAGAG & P. chinensis & Cheng 2011 \\
\hline $21-1$ & PVF1 & GTCGTAGATGAAAACACC & P. khinjuk, P. atlantica, P. vera & \multirow{2}{*}{$\begin{array}{c}\text { Davarynejad et al., 2012; } \\
\text { Esfandiyari et al., 2010; } \\
\text { Yakubov et al., } 2005 \\
\text { Yakubov et al., } 2005\end{array}$} \\
\hline $21-2$ & PVF2 & TAATAGAAGCCATAGA & P. khinjuk, P. atlantica, P. vera & \\
\hline $23-1$ & S1-1 & CGCTCCTTCTAATGTTGATGACAA & P.chinensis & \multirow{2}{*}{ Sun et al., 2014} \\
\hline $23-2$ & S1-2 & TCGCTCССТССАAATCCAATAAAC & P.chinensis & \\
\hline $24-1$ & S281-1 & CCTGGTTGCTTGTGTTGATTAG & P.chinensis & \multirow{2}{*}{ Sun et al., 2014} \\
\hline $24-2$ & S281-2 & GAGTGTCATCAAGCCATCTGTC & P.chinensis & \\
\hline
\end{tabular}

\subsubsection{Primer Design and Confirmation}

All of the specific DNA fragments of different sex types or individuals were individually recovered from agarose gel and purified using a QIAquick Gel Extraction Kit (Aidlab Biotech, Beijing, China). The PCR products were cloned into the pMD19-T vector (Takara, Dalian, China) and then sequenced (Beijing Genome Institute, Beijing, China). Based on the sequences obtained, 16 primer pairs (Table 2) were designed by the Primer Premier 5.0 software and used to re-amplify the same DNA samples. The PCR reactions with the SCAR markers were carried out in a final volume of $25 \mu \mathrm{L}$, containing $50 \mathrm{ng}$ of genomic DNA, 10 pmol of each primer, $2 \mu \mathrm{L}$ dNTPs (2.5 mM each), $2.5 \mu \mathrm{L} 10 \times$ PCR buffer (100 mM Tris-HCl, $\mathrm{pH} \mathrm{8.3,500} \mathrm{mM} \mathrm{KCl}$, and $15 \mathrm{mM} \mathrm{MgCl}_{2}$ ) and $0.5 \mathrm{U}$ Taq polymerase (Takara, Dalian, China). Amplification conditions were one cycle at $94{ }^{\circ} \mathrm{C}$ for $3 \mathrm{~min}$, followed by 32 cycles at $94{ }^{\circ} \mathrm{C}$ for $30 \mathrm{~s}, 51-61{ }^{\circ} \mathrm{C}$ (based on the melting temperatures of the primers) for $30 \mathrm{~s}$, and $72{ }^{\circ} \mathrm{C}$ for $25-40 \mathrm{~s}$ (based on the predicted sequence length). The electrophoresis and observation protocols were the same as described above. The experiments were replicated three times.

Table 2. Primers designed according to the specific Pistacia chinensis sequences.

\begin{tabular}{cc}
\hline Primer & Sequence \\
\hline A1-F & ATACGCCTCAAAATATGCCCCCG \\
A1-R & CGCCAAGTAGTACCCATATTAGTTATTTG \\
A2-F & TGCTGGAGGCAAGGAATCACAT \\
A2-R & CCCACCATCATCGCCTGAATAA \\
A4-F & GCCAAGTAGTACCCATATTAGTTATTTG \\
A4-R & CTCAAAATATGCCCCCGATTCC \\
B1-F & GCCACTTCACAATCTTCCAAA \\
B1-R & ATCCCAACAACAATAAACAAACC \\
B3-F & CCACCAGCGCACGCCATCACCTG \\
B3-R & GGTGGAGATGACGACTGTTTGGATG \\
B6-F & ATGAGTAGAAAGTGGTCCGGGTCAAACCA \\
B6-R & ATTTGTGATGCCGAGTCGGACAGGT \\
C2-F & CGACCCTGGAGCAGCAACACTA \\
C2-R & TCGGTGGGACGACTGGCTTATT \\
C3-F & GCCACACTGGACCCTGCAGATTT \\
C3-R & GGCCAAAATAATTTTCAATAAATAACGG \\
C8-F & CATAGTCGGGGCACGCTCATAC \\
C8-R & AGGGGCTCATTGTCGGGCAGAT \\
D1-F & TTCGAGTTGGCCACGGGGC \\
D1-R & GGCCCTTCTACTTGACTAAGTAGTATTCCACTC \\
D2-F & ACTAGCAGCAGAGCAGTGAACCG \\
D2-R & CAGCCACATCTCCAATCCCTTTT \\
D6-F & CTTCTACTTGACTAAGTAGTATTCCACTC \\
D6-R & CTTCGAGTTGGCCACGGGGCAAC \\
D8-F & CCACGTGTATGGTGGTGATCCATCT \\
\hline
\end{tabular}


Table 2. Cont.

\begin{tabular}{cc}
\hline Primer & Sequence \\
\hline D8-R & TTTCATCAAAAAGAAATCTACCTACAGAG \\
E1-F & GCCACGTCTACAGCAATATAAAAG \\
E1-R & GCAGAAAAATATAGAGCAAGAATCAC \\
E5-F & ACGTGTATGGTGGTGATCCGCTC \\
E5-R & TTTCATCAAAAAATCTACCTACGAAAC \\
E6-F & ACAGCAAAACGACCTCAAAAGG \\
E6-R & GGATGATGGGACGACTAAGCAG \\
\hline
\end{tabular}

\subsection{Sex Expression of Grafted Trees from Scions of Different Sex Types on Monoecious P. chinensis}

The shoots of different sex types (identified by previous flowering observations) were grafted, respectively, from eight monoecious trees, and 6-8-year-old local P. chinensis trees (sex type unknown) were used as rootstocks in 2014, with the aim of obtaining more monoecious trees and determining whether the origin of monoecism was a bud mutation. More than 200 grafted trees were obtained, their scions' sexes were marked, and their sex expressions were observed to determine whether they bloomed in 2016-2017. Due to the long juvenile period of Pistacia species and the difficulty of determining sex before flowering [38], the sex types of the rootstocks and the unflowering grafted trees were unknown.

\subsection{Sex Differences During the Development of Male and Female Inflorescence Buds and Shoots}

\subsubsection{Plant Materials}

The selected monoecious tree was over 40 years old, with male and female inflorescences on separate branches (Figure 1a,b), and the only tree having sex types (bearing male or female flowers) on the branches that were stable in successive years according to previous observations. Flower buds occurred laterally on one-year-old shoots, and both female and male inflorescences had panicles bearing up to several hundred individual florets (Figure 1c,d).
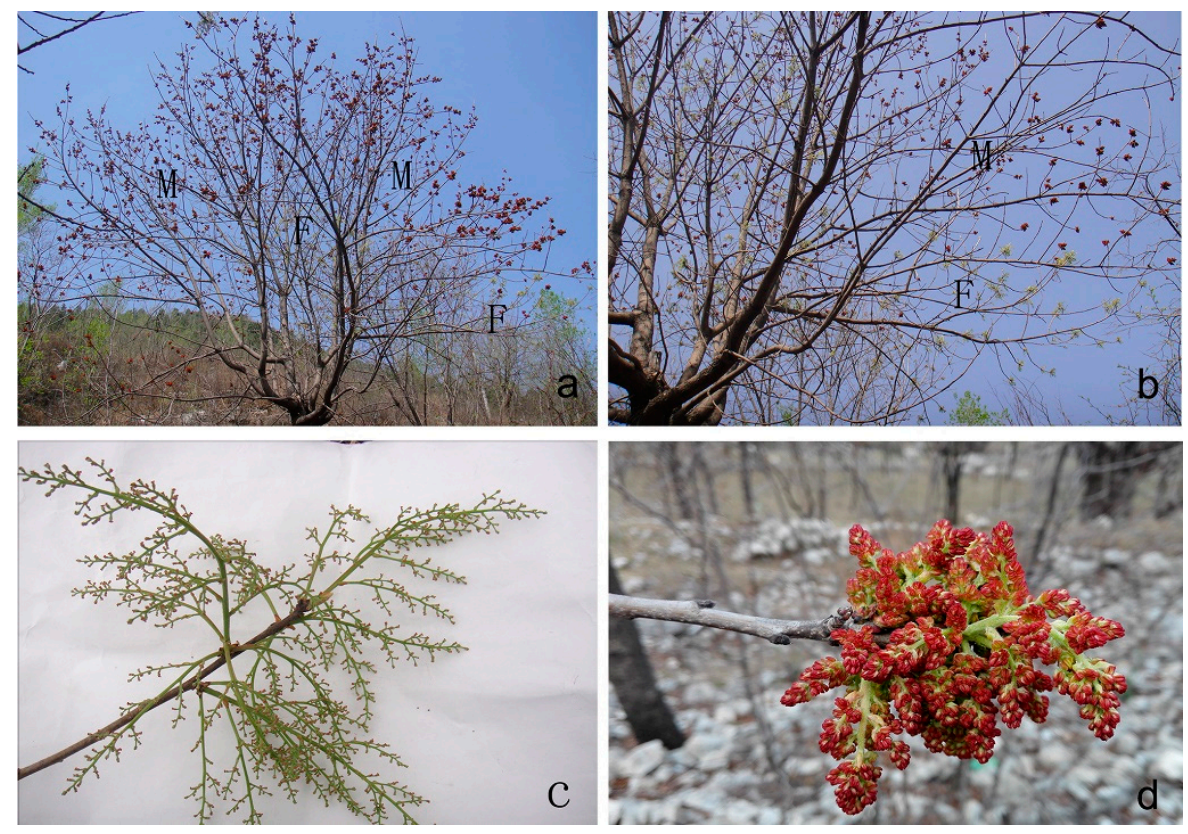

Figure 1. Characteristics of the selected monoecious Pistacia chinensis. Female and male branches of the selected tree (a,b, respectively); female inflorescences (c); and male inflorescences (d). 


\subsubsection{Experimental Methods}

More than 10 buds (inflorescences) from both male and female branches were collected and the phenological phases (dynamic state of development) of shoots bearing male and female flower buds (inflorescences) were recorded from April 2015 to April 2016. After the external forms were photographed, buds were collected and soaked in FAA liquid $(5 \mathrm{~mL}$ formalin, $5 \mathrm{~mL}$ acetic acid, and $90 \mathrm{~mL} \mathrm{70 \%} \mathrm{ethanol).} \mathrm{Then,} \mathrm{paraffin} \mathrm{sections} \mathrm{of} \mathrm{male} \mathrm{and} \mathrm{female} \mathrm{flower} \mathrm{buds} \mathrm{were} \mathrm{made} \mathrm{according} \mathrm{to}$ Zhang's method [36], which included dehydration, embedding, sectioning, and HE staining. The buds (inflorescences) were eventually observed and imaged using an Olympus BH microscope and camera.

\section{Results}

\subsection{Sex Identification Using Molecular Markers}

In total, 24 pairs of primers (Table 1) were used to amplify the genomic DNA obtained from male, female, and different sexes of monoecious P. chinensis. Most of the amplification patterns were indistinguishable between the female and male pooled samples, as well as female, male, and bisexual samples from one monoecious tree (Supplementary Figure S1a).

Among the 24 pairs of primers, OPP-03 was the only primer that could differentiate sex type within the pooled samples. As seen in Supplementary Figure S1b, several bands appeared to be specific to male plants. Furthermore, although there were no differences among the monoecious female, male, and bisexual samples, there were likely to be some differences between monoecious and dioecious plants. However, when the separate samples were tested, the specific bands were different between individuals of the same sex (Supplementary Figure S1c).

The sequences of similar bands from different sexes were compared, and, as a result, some of the sequences from different sexes were the same, while some single-base mutations occurred. Based on the specific sequences, 16 pairs of SCAR primers (Table 2) were designed and used to re-amplify separate DNA samples. Among them, the banding patterns of different DNA samples were the same, except for E5-F/R. Using E5-F and E5-R, different amplification patterns displayed among individuals, but they did not correlate with sex (Figure 2). Despite the polymorphisms among individuals, the banding patterns showed no differences among the different sex types on the same monoecious tree using all of the screened primers (Tables 1 and 2).

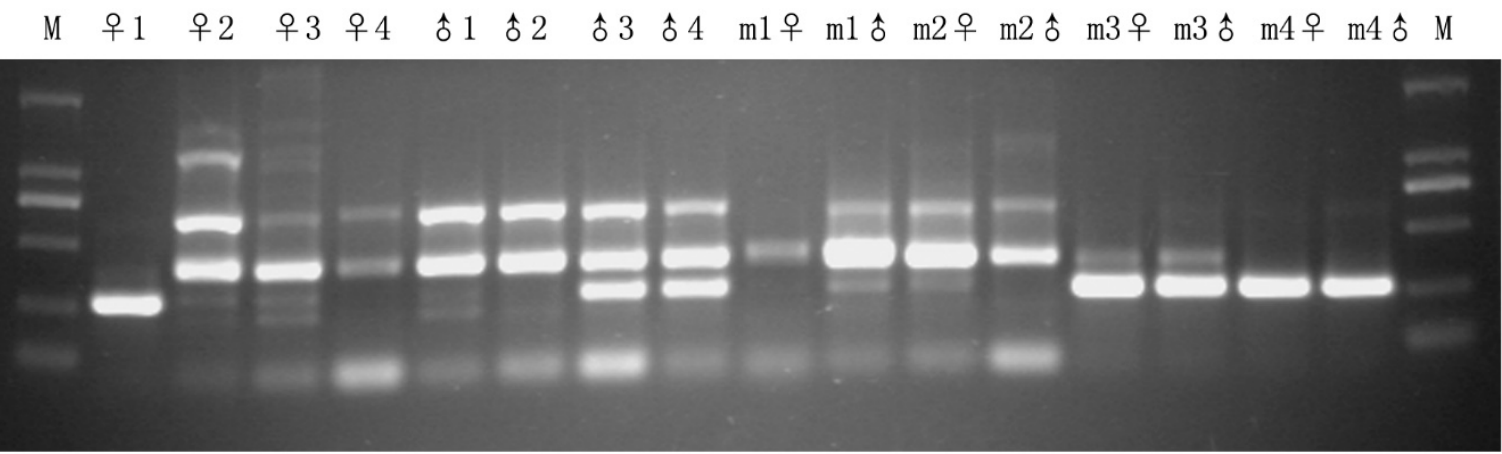

Figure 2. Polymerase Chain Reaction (PCR) banding patterns of DNA samples from four female, male, and monoecious Pistacia chinensis using E5-F/R sequence-characterized amplified region (SCAR) primers.

\subsection{Sex Expression on Grafted Trees}

After grafting different sex types (male, female, and bisexual) of monoecious P. chinensis, 189 grafted trees survived and 13 of them bore flowers and fruit in 2017, while the other surviving trees underwent vegetative growth without flowering. Among the flowering trees, 11 grafted trees bore only female inflorescences (Figure 3a), and the other two trees were monoecious, containing female, 
male, and bisexual florets (Figure 3b). The sex types of the grafted trees were not exactly the same as those of their scions. For the female grafted trees, one of the scions was monoecious, two were male, and eight were female, while the monoecious trees were grafted from male and non-flowering shoots (Table 3).
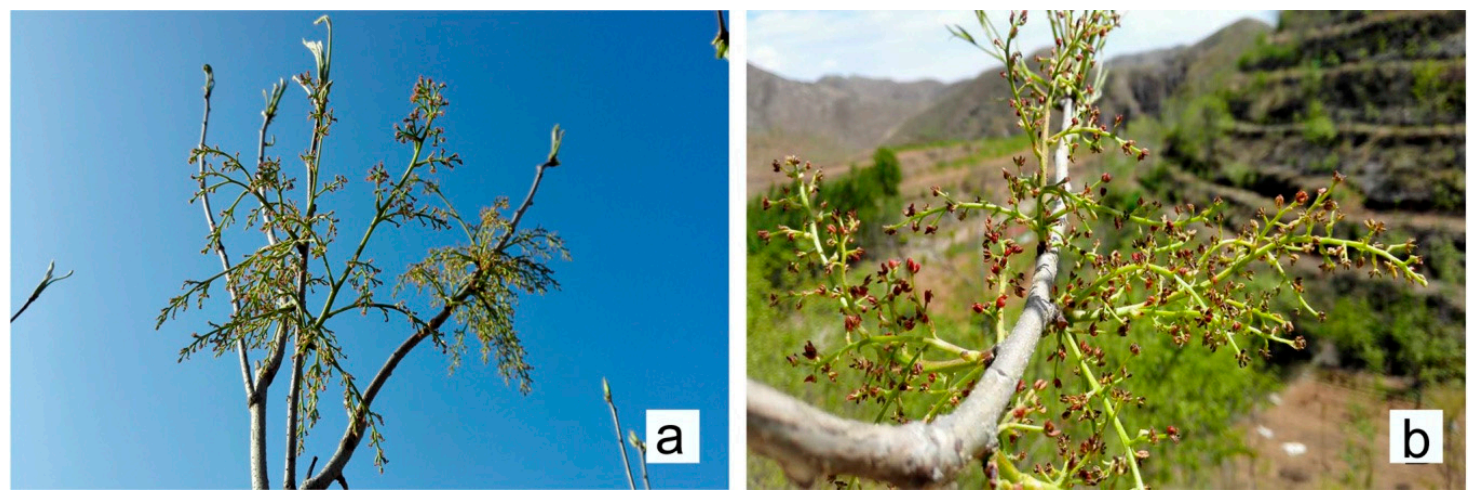

Figure 3. Characteristics of the grafted Pistacia chinensis. Female inflorescences on a female grafted tree (a); and mixed inflorescences on a monoecious grafted tree (b).

Table 3. Sex expression of grafted monoecious Pistacia chinensis.

\begin{tabular}{ccc}
\hline Sex Expression of Scions & Sex Expression of Grafted Trees & Amount \\
\hline monoecious & female & 1 \\
male & female & 2 \\
female & female & 8 \\
male & monoecious & 1 \\
non-flower & monoecious & 1 \\
\hline
\end{tabular}

\subsection{The External and Internal Morphological Differentiation Processes of Male and Female Flower Buds}

To reveal the sex differentiation process, the developmental processes of male and female flower buds (inflorescences) on the same monoecious tree were studied. Both male and female flower buds underwent inflorescence and floret differentiation. The former included bract and shoulder differentiation, while the latter included floret primordia, floret tepal, and pistil or stamen differentiation. To show the sex differences more clearly, we divided the developmental processes into six phases based on anatomical differences: undifferentiated, initial differentiation, sex differentiation, late phase of sex differentiation, sex organ development, and sex gametophyte development, based on the anatomical differences. The corresponding phenological phases and the internal and external form processes were as follows:

\subsubsection{Undifferentiated Phase}

In late April, new buds emerged from new shoots that grew vigorously on female branches, while the male branches underwent this process about ten days later. The buds were small and triangular (Figure 4a), and flower buds were similar to leaf buds in the undifferentiated stage (Figure $4 \mathrm{~b}$ ).

\subsubsection{Initial Differentiation Phase}

In the initial differentiation phase, the differentiation processes of male and female flower buds were similar. Using paraffin sections, it was impossible to distinguish any reproductive structures on the developing inflorescences. To begin, an apical point appeared from the lower area of the bud and slowly grew upwards (Figure 4c). During this period, flower buds were green and thin, slightly bigger than leaf buds, and had tightly closed bud bracts (Figure 4d). Then, the bract differentiation phase started, and a shoulder formed inside each bract (Figure 4e). After that, based on the shoulder, the secondary primordium of the shoulder arose (Figure 4f), and corresponding secondary bracts 
gradually formed outside each secondary shoulder. As the new shoot's growth became more rapid, the buds became larger (Figure $4 \mathrm{~g}$ ). At the same time, secondary bracts continued growing as the secondary shoulders gradually formed and floret primordia emerged (Figure $4 \mathrm{~h}$ ). Next, the periphery of the floret primordium gave rise to several bulges, entering the tepal differentiation phase (Figure 4i).

However, there were significant differences in the time of differentiation between males and females. Most of the female flower buds began differentiation on April 27, while the leaves of new shoots on males had not expanded. Even on May 4, the male flower buds were still less than $2 \mathrm{~mm}$, far smaller than the female flower buds. Nevertheless, almost all the male buds entered the bract differentiation stage on May 17 and entered the floret differentiation stage within only one week.
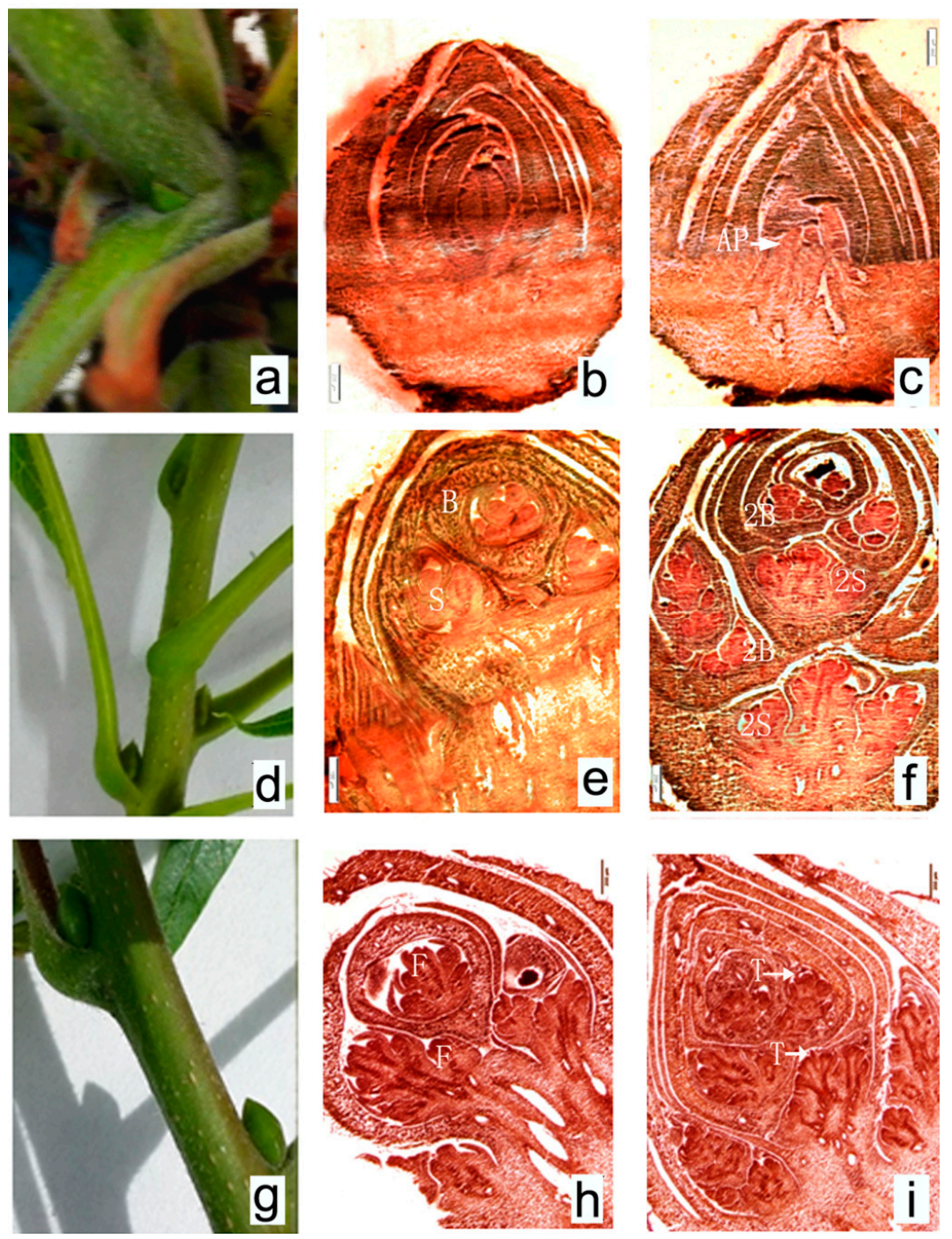

Figure 4. The external and internal morphological changes of flower buds during the undifferentiated and initial phases in monoecious Pistacia chinensis. Undifferentiated phase $(\mathbf{a}, \mathbf{b})$ and initial differentiation phase (c-i). The white marks in these pictures are: AP, apical point; $\mathrm{B}$, bract; $\mathrm{S}$, shoulder; 2B, secondary bract; $2 \mathrm{~S}$, secondary shoulder; F, floret; T, tepal (bar $=200 \mu \mathrm{m})$.

\subsubsection{Sex Differentiation Phase}

Sex differentiation occurred in late May, with buds gradually swelling, bud bracts becoming loose, and male buds becoming fuller than female buds (Figure $5 a, b$ ). When the differentiation of floret tepals was completed, several bulges arose outside the floret primordial base and inside the tepals. The primordium in the middle was that of the pistil, and the peripheral bulges were considered stamen primordia (Figure 5c,d). Despite bisexual structures coexisting during this phase, the growth 
of the alternative sexual structures was inhibited. As the florets continued to develop, the stamen primordia in female buds degenerated into second round tepals, whereas the pistil primordia in male buds aborted on June 8. Additionally, their external shapes became different; the female buds were spindle-like (Figure 5e), while the male buds were fully teardrop-shaped (Figure 5f). As a result, female buds entered the differentiation stage of the second round petals while the first round petals continued to develop (Figure 5g). In contrast, the pistil primordia disappeared in male buds, and the stamen primordia formed anther-like structures on June 16 (Figure 5h).
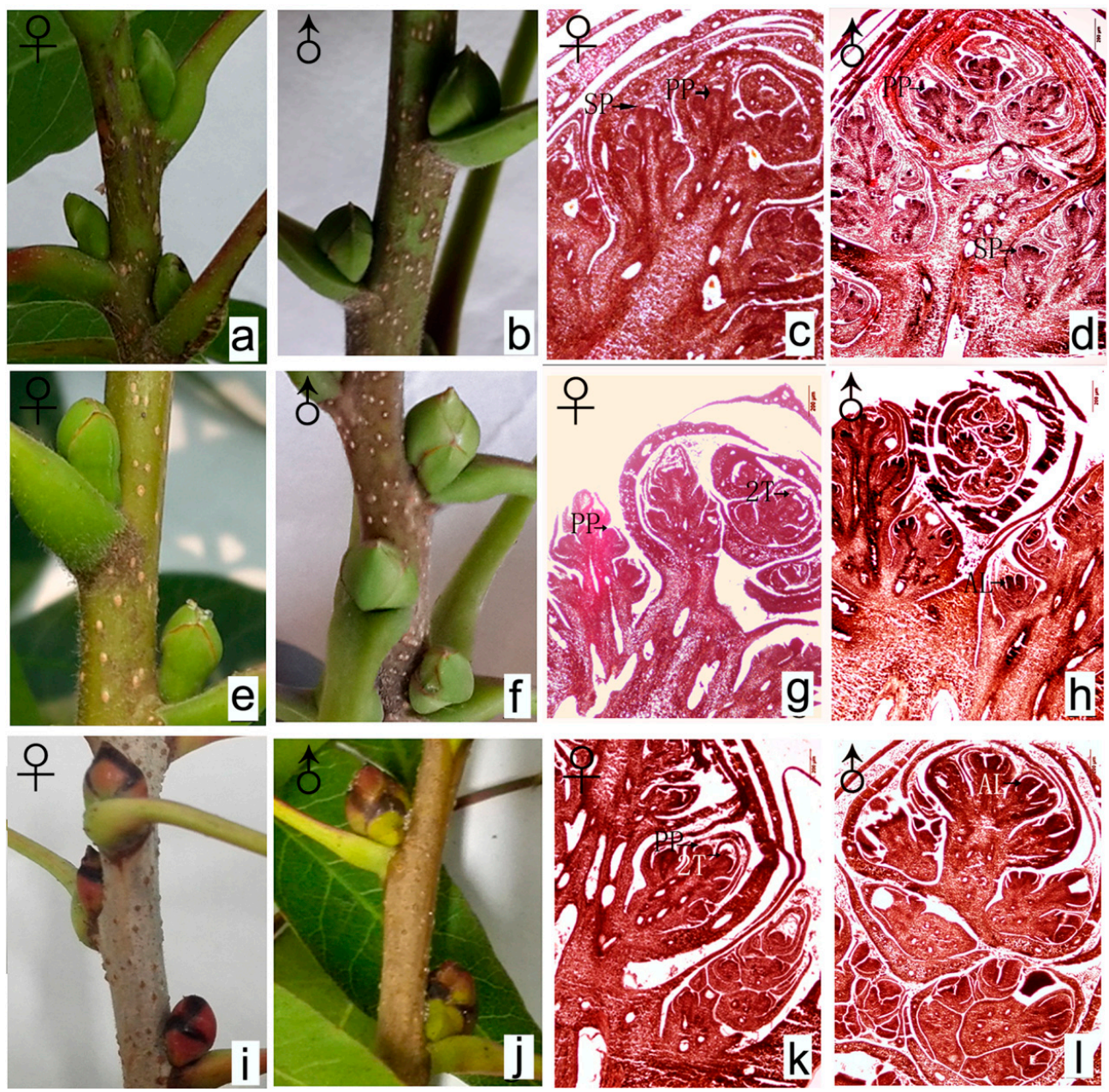

Figure 5. The external and internal morphological changes of female and male flower buds during sex differentiation phases in monoecious Pistacia chinensis. Bisexual stage of sex differentiation (a-d); unisexual stage of sex differentiation $(\mathbf{e}-\mathbf{h})$; and the late phase of sex differentiation (i-1). The marks in these pictures are: PP, pistil primordium; SP, stamen primordia; $2 \mathrm{~T}$, the second round tepal; $\mathrm{AL}$, anther-like structure $(\mathrm{bar}=200 \mu \mathrm{m})$.

\subsubsection{The Late Phase of Sex Differentiation}

After the bisexual structures developed into unisexual organs, the outside bracts became brown and leathery (Figure 5i,j). The bud shapes of both sexes were basically stable but kept expanding. As the secondary tepal differentiation of the female flowers was completed after June 29 , the pistil primordia gradually became plump (Figure 5k). Conversely, the anther-like structures in the male buds became bigger and fuller (Figure 5l), with the male buds constantly expanding, which resulted in the male buds being significantly bigger than the female buds. 
After July 8, the female buds showed no obvious changes, and the growth of male buds aborted after July 25, while external bracts continued to become leathery. Then, the male and female buds entered into the dormancy phase.

\subsubsection{Sex Organ Development Phase}

The dormancy phase lasted for $\sim 4$ months, in which the bracts were hard and closed tightly (Figure 6a,b) and their internal structures remained the same (Figure 6c,d). In mid-March, flower buds of both sexes burst, and the bracts loosened as the inflorescences extended (Figure 6e,f). Carpel primordia emerged and developed from pistil primordia in female florets (Figure 6g), while every anther developed further and formed four pollen sacs (Figure 6h).
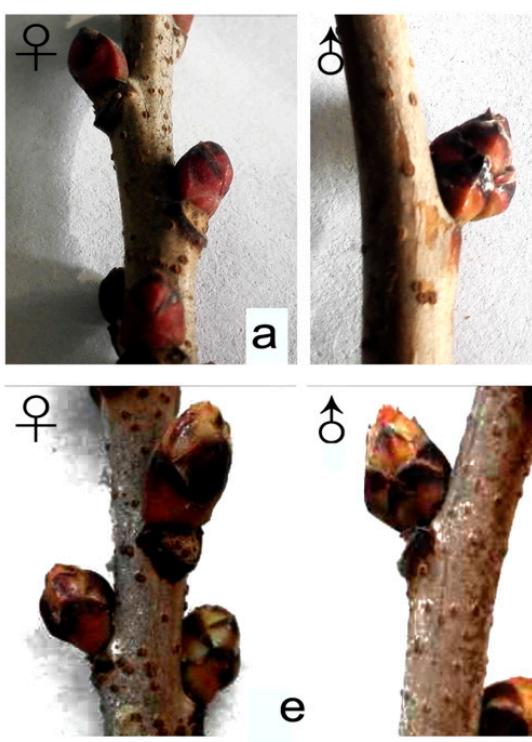

우

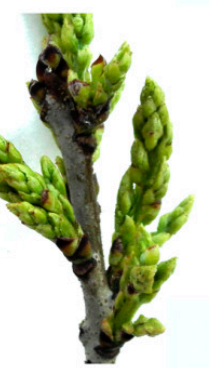

覀

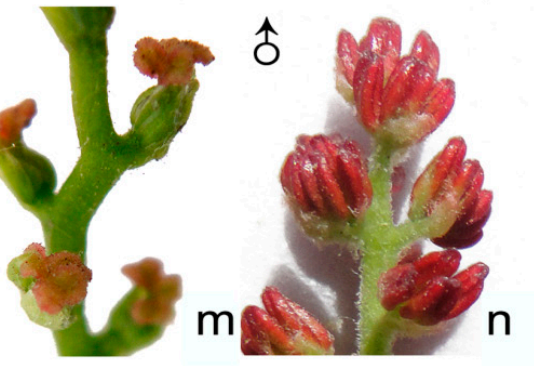

b
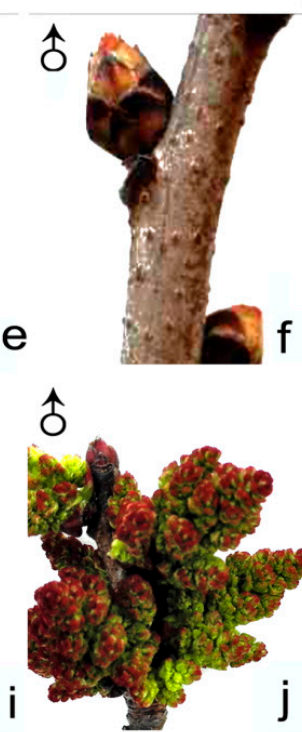
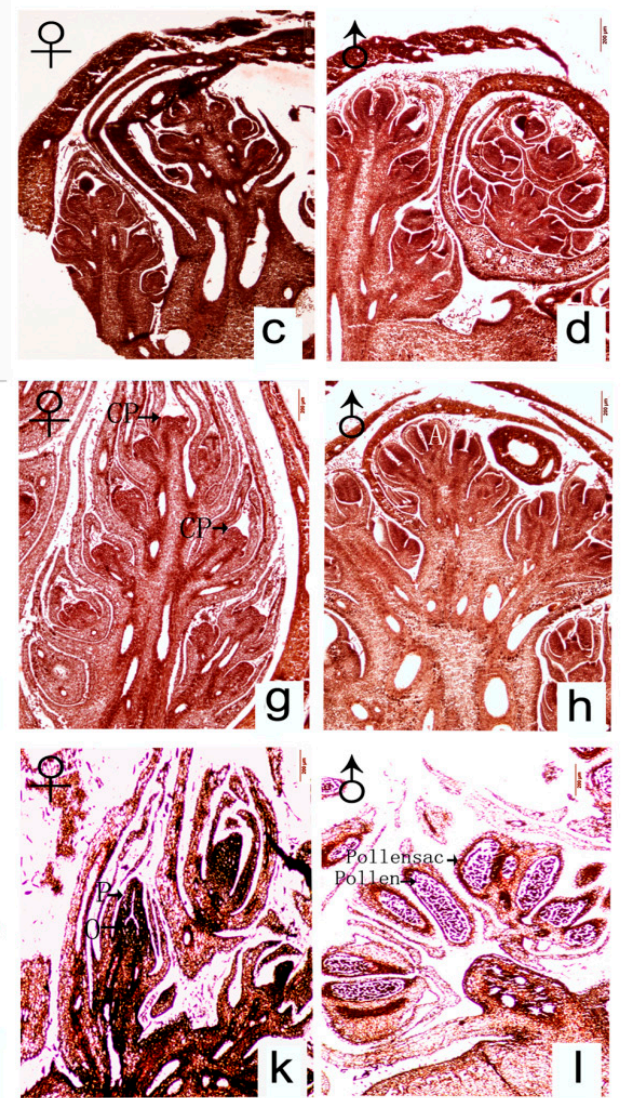

今
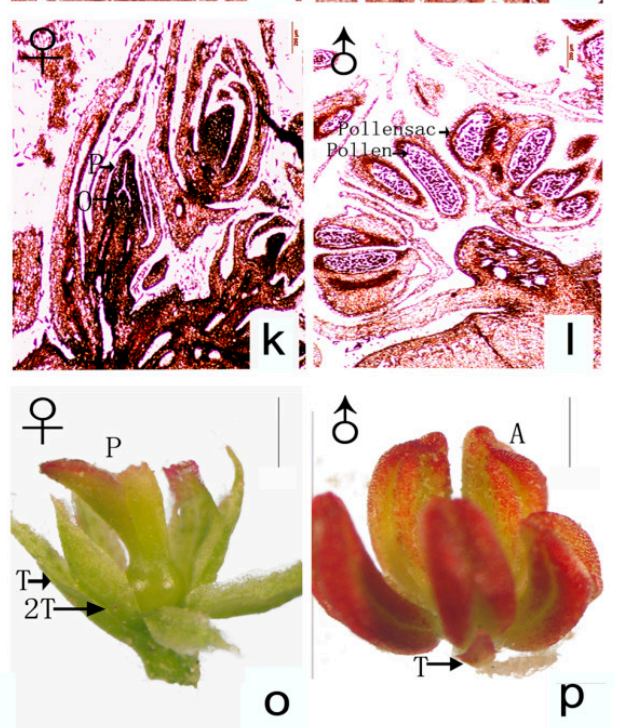

Figure 6. The external and internal morphological changes of female and male flower buds (inflorescences) during the sex organ development phase in monoecious Pistacia chinensis. Dormancy phase (a-d); flower-bud burst stage (e-h); gametophyte development stage (i-1); and floret maturity stage $(\mathbf{m}-\mathbf{p})$. The marks in these pictures are: CP, carpel primordium; $\mathrm{A}$, anther; $\mathrm{P}$, pistil; $\mathrm{O}$, ovule; $\mathrm{T}$, tepal; $2 \mathrm{~T}$, the second round tepal ( $\mathrm{c}, \mathrm{d}, \mathrm{g}, \mathrm{h}, \mathrm{k}$, and $\mathrm{l}$ : bar $=200 \mu \mathrm{m}$; o and $\mathrm{p}$ : bar $=1 \mathrm{~mm}$ ). 


\subsubsection{Sex Gametophyte Development Phase}

As the inflorescences developed, the inflorescence morphology became significantly different between females and males. Female inflorescences were relatively long and thin (Figure 6i) and then spread out, while male inflorescences were compact (Figure 6j). At the same time, the carpels extended, and anatropous ovules were rapidly constructed in female florets (Figure 6k), while the inside of the pollen sacs dissolved and then pollen appeared (Figure 61). When the trifid stigma spread out of the tepals and turned light red, the female had matured (Figure $6 \mathrm{~m}$ ). Figure 60 shows the matured female floret, indicating that there were two sets of tepals in female florets. As shown in Figure $6 n, p$, the matured male floret was dark red, consisting of one set of tepals and 4-6 anthers, and each anther formed four pollen sacs, which were mainly arranged into a butterfly-like shape and were filled with pollen grains. Finally, the anthers dehisced, beginning the pollen dispersal period that occurred during April 14-18 in 2016.

\subsection{Flower Bud Morphological Differentiation and Phenological Phases of Male and Female Shoots}

To determine the morphological and physiological changes that occurred in male and female shoots throughout the year, external phenological and internal development phases were observed from April 2015 to April 2016. As can be seen in Table 4, the female flowers bloomed later, while the female shoots grew earlier than those of the male. With the new shoot growth and spreading of leaves, leaf buds developed into flower buds. In the initial differentiation phase, flower buds were slightly bigger than the leaf buds. In the late stage of sex differentiation, flower buds were significantly larger than leaf buds, and the differences between male and female buds were visible. Additionally, the bracts turned brown and leathery. In the late phase of sex differentiation, flower buds grew slowly or aborted, while the fruit developed until maturity in October. Finally, sex organs and gametophytes started to develop in the second year after breaking dormancy [39]. 
Table 4. Ontogenetic timeline of floral development on monoecious Pistacia chinensis from 2015 to 2016.

\begin{tabular}{|c|c|c|}
\hline Date & Female & Male \\
\hline April 7-April 10 & & Blooming period of male \\
\hline April 11-April 16 & Blooming period of female, and terminal buds burst & \\
\hline Late April & Vegetative phase, and new shoots grew vigorously & \\
\hline April 27 & $\begin{array}{l}\text { Flower bud initial differentiation and new shoot growing phase, leaves spread } \\
\text { out and fruits grew fast }\end{array}$ & Vegetable phase, new shoots grew vigorously and leaves developed \\
\hline May 4 & Bracts and deputy panicle differentiation phase, new shoots stopped growing & \\
\hline May 17 & Floret primordium differentiation phase & Flower bud initial differentiation and new shoot growing phase, leaves spread out \\
\hline May 24 & First round tepal differentiation phase & $\begin{array}{c}\text { Bracts and deputy panicle appeared, floret primordium differentiation, and new shoots } \\
\text { stopped growing }\end{array}$ \\
\hline $\begin{array}{l}\text { Late May } \\
\text { June } 8\end{array}$ & Stamen primordia appeared and fruits stopped growing & Stamen primordia appeared and developed \\
\hline June 16 & & Pistil primordium disappeared, anther-like structures expanded \\
\hline June 29 & Pistil primordium differentiation phase, bracts became brown & \\
\hline $\begin{array}{l}\text { July } 8 \\
\text { July } 16\end{array}$ & $\begin{array}{c}\text { Flower bud stopped growing, bracts continued materialization } \\
\text { Fruit developmental phase }\end{array}$ & Bracts became brown \\
\hline July 25 & $\begin{array}{l}\text { Fruit developmental phase } \\
\text { Fruit-embryo developmental phase }\end{array}$ & Flower bud stopped growing, bracts continued materialization \\
\hline Beginning of October & Fruit maturation, and leaves became yellow & Leaves became yellow \\
\hline November & Leaves fell off and then entered into dormancy period & Leaves fell off and then entered into dormancy period \\
\hline Mid-March & Bud burst stage, pistil differentiation phase, and carpel primordia emerged & Bud burst stage, and anthers developed, and pollen sacs formed \\
\hline Beginning of April & Carpel and ovule appeared, and inflorescences developed & Inflorescences developed and pollen appeared \\
\hline April 14-April 18 & & Blooming period of male \\
\hline April 19-April 25 & Blooming period of female & \\
\hline
\end{tabular}




\section{Discussion}

\subsection{Sex Differences at The Molecular and Phenotypic Levels}

Here, DNA samples of every sex type from dioecious and monoecious P. chinensis were amplified by 24 primer pairs (Table 1) which had previously been used for sex identification in the Pistacia genus. Additionally, 16 SCAR primers (Table 2) were designed based on specific $P$. chinensis sequences. However, no specific bands were accurately distinguished among the different sex types. On the one hand, this may be due to the specificity of the different species, resulting in some primers from other species not being applicable in P. chinensis. On the other hand, some of the so-called sex-specific bands may be the result of polymorphisms between individuals or groups and not related to sex [7]. The functions of the cloned sequences were unknown or not sex associated according to a Basic Local Alignment Search Tool (BLAST) algorithm-based search against the GenBank database. Additionally, two monoecious $P$. vera were tested using the SCAR primers PVF1 and PVF2. One was identified as male, while the other was identified as female [19]. Furthermore, a molecular analysis showed a high level of variability among the tested accessions, including female, male, and monoecious P. terebinthus [7]. Therefore, the DNA differences related to sex may be very small in the Pistacia genus, which would make it difficult to understand sex determination mechanisms using molecular markers. Thus, it might be more fruitful to look at RNA expression during the different ontogenetic stages described in this paper. Sex-specific quantitative transcriptomic data (mRNA and small RNA), which have the time-space specific expression, can be compared to produce a set of candidate genes [12,40-43]. Furthermore, protein is inherently linked to phenotypic differentiation, so the proteomics can provide a fundamental understanding of the biological changes [44]. Hence, proteomic analysis among different sex types during sex differentiation phases could offer more clues on sex differentiation. To have a global view on sex determination, subsequent research could integrate multi-omics and multiple levels of morphology, cytology, physiology, and molecular biology.

Although the genetic analysis yielded no promising results, differences in the timing and the inner and external morphology were found between the sexes of monoecious $P$. chinensis during floral development for the first time. Additionally, the developmental processes of monoecious female buds were consistent with those of dioecious female buds [36]. The differences between males and females suggested that sex was determined during bud development in monoecious P. chinensis. Additionally, the bud differentiation period can be preliminarily determined based on the external form, allowing the formulation for future work based on identifying the timeline of floral development.

\subsection{Possible Formation Mechanisms of Monoecious P. chinensis}

The banding patterns were consistent among different parts of a monoecious tree using all of the screened primers (Supplementary Figure S1, Figure 2), indicating that the DNA fragments from parts of the same monoecious $P$. chinensis having different sexes may not show any differences. In other words, the gene sequences might be the same on a monoecious tree. Conversely, the sex expressions of grafted trees were not consistent with those of the scion shoots, which may result from the instability of the sex for the scions themselves, or the effect of the external environment or internal physiology, such as hormones and nutrients after grafting. Moreover, previous observations indicated that the sex types of single shoots on a monoecious plant can change within one year [11]. These phenomena reveal that the origin of monoecism was not a bud mutation, which is permanent and can be retained and perpetuated by grafting. In this case, it is more likely that the differential expression of gene(s), rather than the DNA mutation, results in the sex difference, indicating that sex determination may occur during flower bud differentiation instead of at an earlier stage.

The floral developmental process showed that the alternative sex-related organs coexist in the early sex differentiation phase in P. chinensis (Type 2), so the key period of sex determination should be the transition period from the bisexual to unisexual phase. To the best of our knowledge, all of the Pistacia species initially have opposing sex primordia but they arrest in the early or later developmental 
stages $[2,33]$. These phenomena indicate that sex determination can take place during different developmental stages, with the critical period for sex determination being early in $P$. chinensis, which is similar to P. vera [34]. More importantly, the emergence of monoecism, especially bisexual florets, has been identified [11]. It is presumed that all of the Pistacia species evolved from hermaphroditic ancestors and that they have the potential to become monoecious, or even hermaphroditic, if the abortion of opposing sex organs can be stopped. Regardless of whether the monoecism is an atavistic or evolutionary case, the bisexual stage and the rapid sex reversal suggest that $P$. chinensis plants probably have the genetic basis for bisexual flowers, and environmental factors or hormones may influence the sex transition by epigenetic regulation.

To date, multifarious epigenetic mechanisms have been described, involving RNA interference, DNA methylation, and histone modification [45,46]. Additionally, Pannell [31] has argued that non-genetic cues might easily be converted into genetic switches, and numerous studies have proved that environmental factors can induce the sex transition of plants [47-49]. Besides, the sexes of some dioecious species can be changed by the use of certain plant growth regulators or by technical measures [34]. Based on this study, it is clear that environmental factors have played an important role in the final sex expression. The sex differentiation may link to certain environmental parameters, such as temperature and precipitation, but we failed to present the corresponding environmental parameters during the floral development due to the differences in developmental processes among individuals. To further understand the sex determination mechanism and develop plant sex control technology, differentially expressed genes, hormones, nutrients, and environmental parameters should be studied.

\section{Conclusions}

In conclusion, the results ruled out the hypothesis that monoecism originates from a bud mutation, suggesting that sexes were determined during floral development and may be affected by environmental factors. This study determined the critical period of sex differentiation in inflorescence buds and uncovered the internal and external differences between male and female buds on the same monoecious P. chinensis. Additionally, monoecious materials were obtained through graft propagation. These findings and resources can provide the foundation for further exploration of sex determination mechanisms and the utilization of monoecious P. chinensis.

Supplementary Materials: The following are available online at http:/ / www.mdpi.com/1999-4907/10/3/202/s1, Figure S1: Polymerase Chain Reaction (PCR) banding patterns of DNA samples from female, male and monoecious Pistacia chinensis Bunge.

Author Contributions: Conceptualization, S.S. and Q.B.; methodology, Q.B.; software, Q.B.; validation, C.Z., X.L., and T.C.; formal analysis, Q.B.; investigation, Q.B., C.Z., X.L., and T.C.; resources, S.S. and P.L.; data curation, Q.B., C.Z., X.L., and T.C.; writing-original draft preparation, Q.B.; writing-review and editing, S.S. and P.L.; visualization, Q.B.; supervision, S.S.; project administration, S.S. and P.L.; funding acquisition, S.S. and P.L.

Funding: This research was funded by the Fundamental Research Funds for the Central Universities, grant number 2015ZCQ-LX-02; the Special Project of International Cooperation Ministry of Science and Technology, grant number 2014DFA31140; and the Project of Construction of Innovative Teams and Teacher Career Development for Universities and Colleges under Beijing Municipality, grant number IDHT20150503.

Acknowledgments: We thank International Science Editing and MDPI for language editing.

Conflicts of Interest: The authors declare no conflict of interest. The funders had no role in the design of the study; in the collection, analyses, or interpretation of data; in the writing of the manuscript, or in the decision to publish the results. 


\section{References}

1. Dong, S.B.; Liu, Y.L.; Xiong, B.; Jiang, X.N.; Zhang, Z.X. Transcriptomic analysis of a potential bioenergy tree, Pistacia chinensis Bunge, and identification of candidate genes involved in the biosynthesis of oil. BioEnergy Res. 2016, 9, 740-749. [CrossRef]

2. Wang, T. Situation and prospect of major woody energy plants resources for biomass fuel oil in China. Sci. Technol. Lead. 2005, 23, 12-14.

3. Zohary, M. A monographical study of the genus Pistacia. Palest. J. Bot. Jerus. Ser. 1952, 5, 187-228.

4. Özbek, S.; Ayfer, M. A hermaphrodite Pistacia found in the vicinity of Antep, Turkey. Proc. Am. Soc. Hort. Sci. 1958, 72, 240-241.

5. Crane, J.C. Hermaphroditism in Pistacia. Calif. Agric. 1974, 28, 3-4.

6. Kafkas, S.; Perl-Treves, R.; Kaska, N. Unusual Pistacia atlantica Desf. monoecious sex types in the Yunt Mountains of the Manisa province of Turkey. Isr. J. Plant Sci. 2000, 48, 277-280. [CrossRef]

7. Avanzato, D.; Quarta, R. Monoecious Pistacia terebinthus found in Bulgari. Crop Wild Relat. 2004, 2, 14-16.

8. İsfendiyaroğlu, M. Hermaphroditism in Pistacia atlantica Desf.: A New Report from Izmir/Turkey. Ege Univ. Ziraat Fak. Derg. 2007, 44, 1-12.

9. Hou, L.H. Monoecious "energy" tree in the wild. In Forestry Chapter of Anyang Yearbook; Zhongzhou Ancient Books Publishing House: Anyang, China, 2009; p. 155.

10. Zhao, Z.Z. Early report the inflorescence observation of hermaphrodite Pistacia. J. For. Sci. Technol. 2011, $2,47$.

11. Bai, Q.; Su, S.C.; Lin, Z.; Leng, P.S.; Wang, W.H. The Variation Characteristics and Blooming Phenophase of Monoecious Pistacia chinensis Bunge. HortScience 2016, 51, 961-967. [CrossRef]

12. Wang, W.W.; He, H.; Bai, Q.; Qi, P.; Su, S.C.; Fu, X.; Chen, F. Hermaphroditism and Fertility in Pistacia chinensis Bunge. Acta Hort. ISHS 2015, 1074, 129-133. [CrossRef]

13. Wang, G.P.; Kong, D.J.; Liu, Q.X. Advances in research on the relationship between mineral nutrient and bud flower differentiation of fruit trees. J. Yunnan Agric. Univ. JCR-SCI 2009, 24, 908-912.

14. Abe, K.; Oshima, M.; Akasaka, M.; Konagaya, K.I.; Nanasato, Y.; Okuzaki, A.; Taniguchi, Y.; Tanaka, J.; Tabei, Y. Development and characterization of transgenic dominant male sterile rice toward an outcross-based breeding system. Breed. Sci. 2018, 68, 248-257. [CrossRef] [PubMed]

15. Hormaza, J.I.; Dollo, L.; Polito, V.S. Identification of a RAPD marker linked to sex determination in Pistacia vera using bulked segregant analysis. Theor. Appl. Genet. 1994, 89, 9-13. [CrossRef] [PubMed]

16. Kafkas, S.; Cetiner, M.S.; Perl-Treves, R. RAPD markers linked to sex in the genus Pistacia. Plant Prod. Protect. Div. 2001, 56, 251-255.

17. Tan, D.M.; Luo, S.P.; Li, J.; Han, H.T. Sex identification of Pistachio by using RAPD analysis. J. Fruit Sci. 2003, 20, 124-126.

18. Avanzato, D.; Quarta, R.; Vendramin, E.; Djouvinof, V. Osservazioni morfologiche e molecolari su accessioni monoiche di Pistacia terebinthus L. In Proceedings of the Atti VII Giornate SOI, Napoli, Italy, 4-6 May 2004; pp. 1-496.

19. Yakubov, B.; Barazani, O.; Golan-Goldhirsh, A. Combination of SCAR primers and Touchdown-PCR for sex identification in Pistacia vera L. Sci. Horticult. 2005, 103, 473-478. [CrossRef]

20. Andinova, T.; Vendramin, E.; Micali, S. Molecular characterization of Pistacia genus using RAPD markers. G22. In Proceedings of the Atti 50 Congresso Annuale SIGA, Ischia, Italy, 10-14 September 2006. Abstract.

21. Ehsanpour, A.A.; Tavassoli, M.; Arab, L. Sex determination of Pistacia vera L. using ISSR markers. Malays. Appl. Biol. 2008, 37, 25-28.

22. Esfandiyari, B.; Nejad, G.H.D.; Kiani, F.A.S.M. Sex determination in Pistacia species using molecular markers. Compliment. Copy 2010, 12, 122-124. [CrossRef]

23. Cheng, S.P. Tissue Culture and Rapid Propagation of Cotyledonary Nodes and Sex Identification of Pistacia chinensis Bunge. Master's Thesis, Henan University of Science and Technology, Luoyang, China, 2011.

24. Davarynejad, G.H.; Shahriari, A.F.; Kiani, F.M. Data to the sex determination in Pistacia species using molecular markers. Euphytica 2012, 185, 227-231.

25. Sun, Q.; Yang, X.; Li, R. SCAR marker for sex identification of Pistacia chinensis Bunge (Anacardiaceae). Genet. Mol. Res. 2014, 13, 1395-1401. [CrossRef] [PubMed] 
26. Kamiab, F.; Ebadi, A.; Panahi, B.; Tajabadi, A. RAPD Analysis for Sex Determination in Pistacia vera L. J. Nuts 2014, 5, 51-55.

27. Kafkas, S.; Khodaeiaminjan, M.; Guney, M.; Kafkas, E. Identification of sex-linked SNP markers using RAD sequencing suggests $\mathrm{ZW} / \mathrm{ZZ}$ sex determination in Pistacia vera L. BMC Genom. 2015, 16, 98. [CrossRef] [PubMed]

28. Khodaeiaminjan, M.; Kafkas, E.; Güney, M.; Kafkas, S. Development and linkage mapping of novel sex-linked markers for marker-assisted cultivar breeding in pistachio (Pistacia vera L.). Mol. Breed. 2017, $37,98$. [CrossRef]

29. Heikrujam, M.; Sharma, K.; Prasad, M.; Agrawal, V. Review on different mechanisms of sex determination and sex-linked molecular markers in dioecious crops: A current update. Euphytica 2015, 201, 161-194. [CrossRef]

30. Charlesworth, D. Plant sex determination and sex chromosomes. Heredity 2002, 88, 94-101. [CrossRef] [PubMed]

31. Pannell, J.R. Plant Sex Determination. Curr. Biol. 2017, 27, R191-R197. [CrossRef] [PubMed]

32. Matsunaga, S.; Kawano, S. Sex determination by sex chromosomes in dioecious plants. Plant Biol. 2001, 3 , 481-488. [CrossRef]

33. Bachelier, J.B.; Endress, P.K. Development of inflorescences, cupules, and flowers in Amphipterygium and comparison with Pistacia (Anacardiaceae). Int. J. Plant Sci. 2007, 168, 1237-1253. [CrossRef]

34. Hormaza, J.I.; Polito, V.S. Pistillate and staminate flower development in dioecious Pistacia vera (Anacardiaceae). Am. J. Bot. 1996, 83, 759-766. [CrossRef]

35. Zhang, Y.Q.; Qi, G.H.; Li, B.G.; Guo, S.P.; Qi, K.; Yin, Y.J. Study on the development process of leaf bud in Pistacia chinensis Bunge. J. Anhui Agric. Sci. 2011, 21, 12924-12926.

36. Zhang, Y.Q.; Qi, G.H.; Li, B.G.; Guo, S.P.; Zhang, X.M.; Qi, K. Female Flower Bud Differentiation in Pistacia chinensis. Acta Bot. Boreal-Occident. Sin. 2011, 31, 972-976.

37. Copeland, H.F. The reproductive structures of Pistacia chinensis (Anacardiaceae). Phytomorphology 1955, 5, $440-449$.

38. Hormaza, J.I.; Wünsch, A. Pistacia. In Wild Crop Relatives: Genomic and Breeding Resources; Kilian, B., Mammen, K., Eds.; Springer: Berlin/Heidelberg, Germany, 2011; pp. 119-128.

39. Qiu, Z.F.; Li, B.G.; Gu, Y.H.; Li, Y.C.; Zhang, Y.Q.; Qi, K. Megasporogenesis, microsporogenesis and development of female and male gametophyte of Pistacia chinensis Bunge. Acta Bot. Boreal-Occident. Sin. 2010, 7, 1359-1365.

40. Wang, Z.C.; Liu, Q.G.; Xu, X.M.; Yang, J.L.; Zhang, T.; Li, C.H. Identification of microRNAs associated with male flower bud development of Populus simonii x Populus nigra. Trees Struct. Funct. 2015, 29, 1329-1339. [CrossRef]

41. Kersten, B.; Pakull, B.; Fladung, M. Genomics of sex determination in dioecious trees and woody plants. Trees Struct. Funct. 2017, 31, 1113-1125. [CrossRef]

42. Li, W.X.; He, Z.C.; Zhan, L.; Lu, Z.G.; Xu, J.; Cui, J.E.; Wang, L.; Jin, B. miRNAs involved in the development and differentiation of fertile and sterile flowers in Viburnum macrocephalum $\mathrm{f}$. keteleeri. BMC Genom. 2017, 18, 783. [CrossRef] [PubMed]

43. Li, X.B. Next-generation Sequencing Sheds New Light on Small RNAs in Plant Reproductive Development. Curr. Issues Mol. Biol. 2018, 27, 143-170. [CrossRef] [PubMed]

44. Tsou, C.C.; Tsai, C.F.; Tsui, Y.H.; Sudhir, P.R.; Wang, Y.; Chen, Y.; Chen, J.Y.; Sung, T.Y.; Hsu, W.L. IDEAL-Q: An automated tool for label-free quantitation analysis using an efficient peptide alignment approach and spectral data validation. Mol. Cell Proteom. 2010, 9, 131-144. [CrossRef] [PubMed]

45. Iglesias, F.M.; Cerdán, P.D. Maintaining Epigenetic Inheritance During DNA Replication in Plants. Front. Plant Sci. 2016, 7, 38. [CrossRef] [PubMed]

46. Yaish, M.W. Editorial: Epigenetic Modifications Associated with Abiotic and Biotic Stresses in Plants: An Implication for Understanding Plant Evolution. Front. Plant Sci. 2017, 8, 1983. [CrossRef] [PubMed]

47. Glawe, G.A.; de Jong, T.J. Environmental conditions affect sex expression in monoecious, but not in male and female plants of Urtica dioica. Sex. Plant Reprod. 2005, 17, 253-260. [CrossRef] 
48. Martin, A.; Troadec, C.; Boualem, A.; Rajab, M.; Fernandez, R.; Morin, H.; Pitrat, M.; Dogimont, C.; Bendahmane, A. A transposon-induced epigenetic change leads to sex determination in melon. Nature 2009, 461, 1135-1138. [CrossRef] [PubMed]

49. Sinclair, J.P.; Emlen, J.; Freeman, D.C. Biased sex ratios in plants: Theory and trends. Bot. Rev. 2012, 78, 63-86. [CrossRef] 